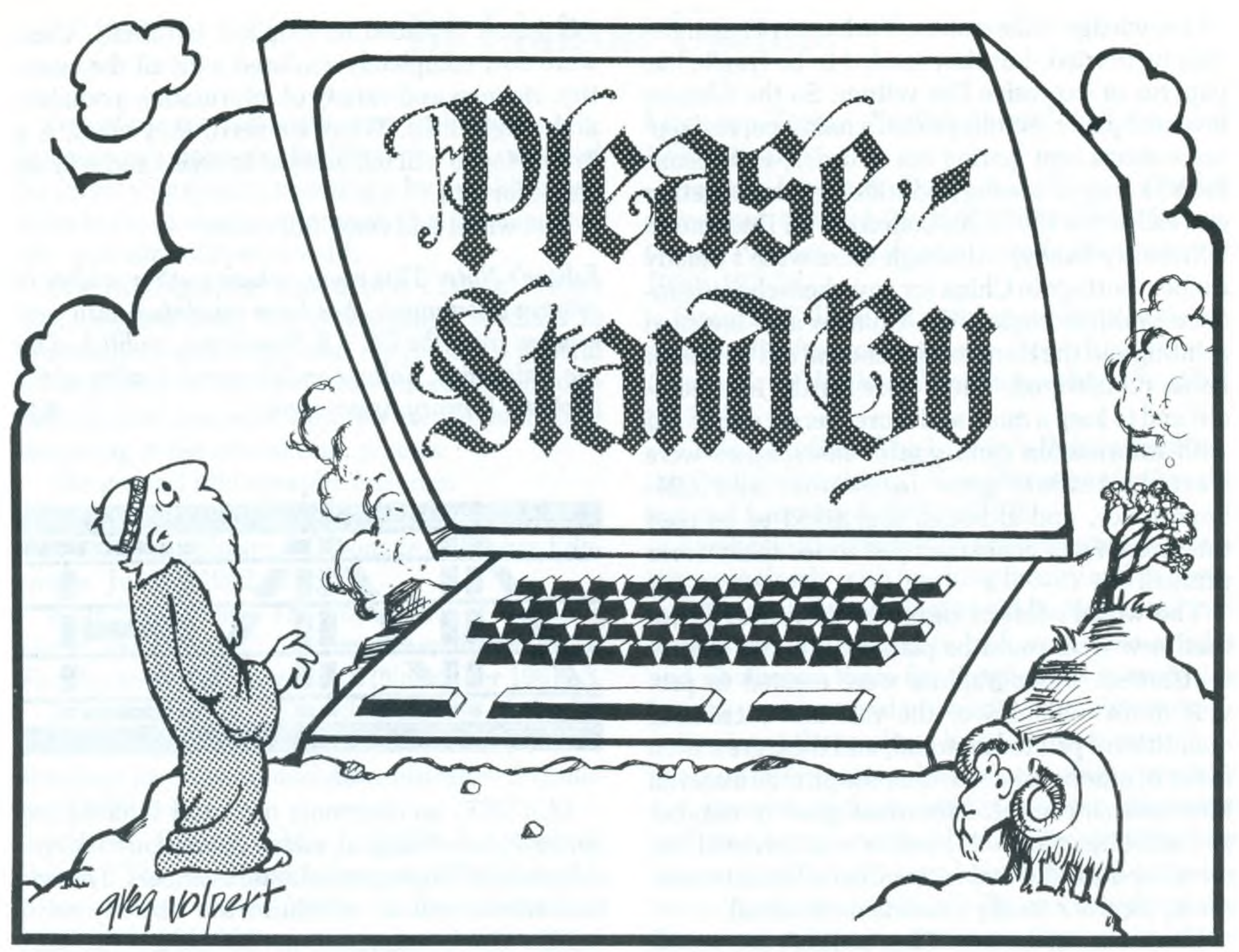

\title{
From Moses to Megabytes:
}

\section{A Short History of Online Information Access}

Moses was having trouble with his followers' morals. They kept on coveting their neighbors' wives and asses (usually in that order), working on the seventh day, and making graven images, not to mention stealing, committing adultery and killing. He issued guidelines from time to time and introduced sanctions, but they all gave the impression of improvisation. He needed something more authoritative.

So he thought he would go and log on to the ultimate source of wisdom, the Great Online Database (GOD), sometimes also called the Grand Old Datalink. The only terminal within reasonable reach was up a mountain, where it was safer from vandalism and unofficial use. (There was another terminal, made by Bush, which caught fire and came to be remembered as the Burning Bush, but the less said about that the better). Moses was a bit rusty with the procedures, but the system was userfriendly and interactive, and Moses was soon able to say what he needed-a fairly short set of rules. One by one they were displayed on the terminal.

"Oh GOD," keyed in Moses, "I'll never remember all that, and in any case the people will need some proof. Can I have a printout?"
"Regret only form of material available at your terminal as a physical printout medium," replied GOD, "is stone."

"That will have to do," keyed in Moses.

So, with the old-fashioned chisel printers around in those days, the stones were slowly engraved with the Ten Commandments, and Moses struggled slowly down the mountain with them. The people were convinced, and felt more guilty thereafter when they coveted, worked on the seventh day, etc., etc.

The stone printout had the excellent feature of permanence but was very heavy to carry around, and as Moses had to keep moving from one place to another, he began to look around for a lighter substitute. His mind went back to his earliest infancy. The bulrushes wouldn't do, but what about the papyrus nearby? That proved to be just the thing, although the ink tended to run when they crossed the river or whenever the heavens opened. So they built a shrine (this was the first library, though it wasn't called that).

Centuries passed. The terminal on Mount Sinai became obsolete, and in their wanderings and battles the Hebrews forsook GOD-indeed, they lost 
all knowledge of the system. Various writing materials were tried, but they tended to be fragile like papyrus or expensive like vellum. So the Chinese invented paper. Scrolls proved a nuisance, and separate sheets kept getting out of order, so someone found a way of sewing and sticking them together and called it a CODEX (Collection Of Documents EXtremely handy). Although there wasn't exactly a labor shortage in China (or anywhere else) to produce multiple copies, the Chinese also invented printing and the Europeans went and did the same. Books proliferated. These were for the intellectuals, and to keep a more and more literate public fed with information (and gossip) newspapers were started. Authors grew in number and selfimportance, and although they liked to be read they were more concerned just to see their works printed.

The world's forests began to disappear faster than new trees could be planted. Library shelves overflowed. Bibliographies were created to provide more control over the vast and increasing quantities of printed material, and these grew even faster in number and size than the printed material they tried to control. Librarians grew in number and self-importance. Microfilm was invented but served as an additional rather than alternative medium, ideal for totally unreadable material.

Users were in despair. They couldn't keep track of what was being produced that they ought to read, let alone find time to read it, and when they wanted something badly they couldn't always get it quickly enough, especially as their libraries failed more and more dismally to keep pace with world output. Abstracts were invented, but these whetted users' appetites still more without really satisfying them, like advertisements for unavailable goods.

Meanwhile computers were invented. They were used to produce bibliographies more quickly and with more up-to-date indexes. These consumed an ever increasing proportion of library budgets, so that they could afford to buy even less of the literature covered by the bibliographies. So the bibliographies were made available online, which cost so much that the money available to buy literature was still further reduced. Librarians were in despair.

Publishers too were in despair, and started to make their products available online in the hope of building up a second market alongside the failing one for printed literature. Access cost so much that...

Alternative media were now competing for the market-various forms of sound and vision, and mixtures of sound and vision. The world was overflowing with information.

Meanwhile, up in the heavens, satellites had begun to reappear (GOD was of course accessed via satellite all those thousands of years ago). Information could be transmitted from almost anywhere instantly (although so far as I know Mount Sinai still hasn't replaced its long-lost terminal). Users were now completely confused with all the quantity, richness and variety of information available, and sought help. What we need, they cried, is a Prophet who will tell us what to access and will access it for us.

The wheel had come full circle.

Editor's Note: This essay, whose author wishes to remain anonymous, has been reprinted with permission from the $\mathrm{UC}+\mathrm{R}$ Newsletter, published by the University, College and Research Section of the (British) Library Association.

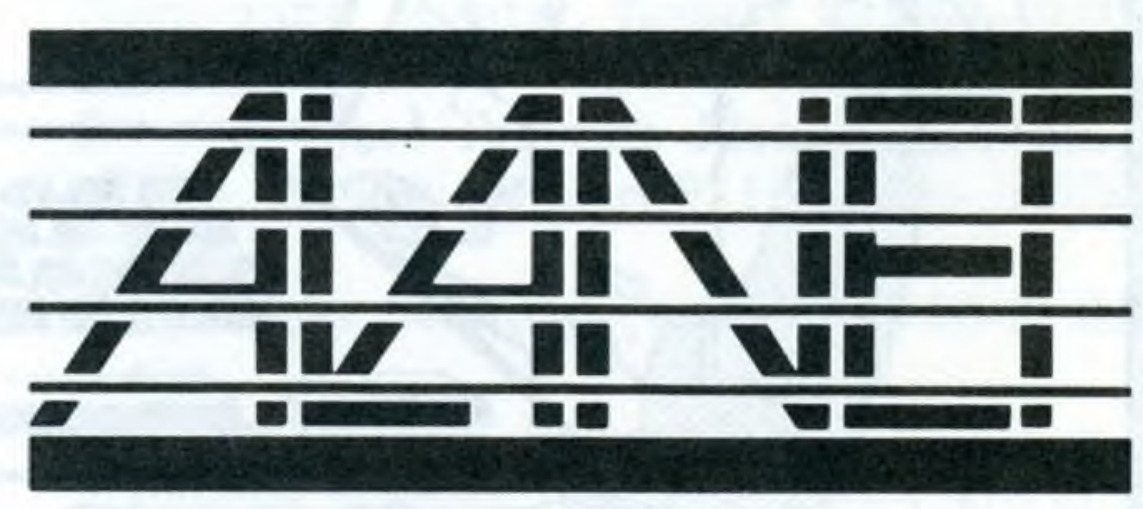

ALANET, an electronic mail and information network, now brings an added dimension to the resources of ACRL organizational members. The system allows you to communicate directly with ACRL/ALA headquarters in Chicago and the ALA Washington Office. ALANET's computer-based services allow dial-up access via Telenet, Tymnet, Uninet, and TWX. ACRL organizational members without computer terminals or those wishing to upgrade their systems, are eligible to receive discounts on computer hardware arranged by ALA.

Electronic mail for ACRL Headquarters can be addressed to ALA0100, ACRL's ALANET identification number. The C $b R L$ News ID is ALA0306. Subscribers can also communicate with anyone else on the subscriber list and with a number of vendors.

A number of databases can also be accessed through ALANET: ALA Washington Newsline, Conference '84 Program Schedules, Intellectual Freedom Alert, the Official Airlines Guide, the UMI Article Clearinghouse, and the UPI wire service.

The system will be officially online on January 1 , 1984. A one-time sign-up fee of $\$ 30$ starts a subscription to ALANET and provides up to three IDs and passwords, account and mail directory set-up, and training materials. A $\$ 7.50$ monthly billing fee (\$90 annually paid in advance) covers account maintenance. ALA will invoice subscribers monthly for their use of the system, based on connect hour costs ranging from $\$ 17$ to $\$ 20$ per hour. Only ALA organizational members can subscribe to ALANET.

For more information contact ALANET System Manager Joel M. Lee, ALA Headquarters Library, 50 E. Huron St., Chicago, IL 60611; (312) 9446780 . 